\title{
PROPRIEDADES FÍSICO-QUÍMICAS DAS BEBIDAS À BASE DE SOJA
}

Amanda Rossi CORELHANO, Fernando MEZONI, Judith Angelica Gonzales SULLCAHUMÁN, Elaine Machado BENELLI, Fernanda Morais FERREIRA, Fabian Calixto FRAIZ

As lesões erosivas do esmalte dental podem estar relacionadas com 0 aumento do consumo de bebidas industrializadas à base de soja. $\mathrm{O}$ objetivo deste trabalho foi avaliar o $\mathrm{pH}$ e a capacidade tampão de bebidas à base de soja presentes no mercado nacional. Para tal, foram utilizados nove sabores de bebidas à base de soja $(\mathrm{ADES} \AA)$ : frapê de côco, maracujá, laranja, uva, abacaxi, morango, pêssego, vitamina de banana e maçã. $\mathrm{O}$ pH destas soluções foi determinado utilizando um potenciômetro WVT 330i. As bebidas foram tituladas pela adição seqüencial de $100 \mu \mathrm{l}$ de $\mathrm{NaOH} 0,1 \mathrm{M}$ até que $\circ \mathrm{pH}$ atingisse um valor de 7,4 ou imediatamente superior. Todo o experimento foi realizado em duplicata e foram avaliados dois lotes distintos do mesmo sabor de cada bebida. O suco que apresentou a maior capacidade tampão foi o de sabor abacaxi e a menor capacidade tampão foi encontrada nos sabores vitamina de banana e frapê de côco. Pode-se concluir que mesmo nos sabores com baixo $\mathrm{pH}$ inicial a capacidade tampão foi baixa, minimizando os riscos da erosão dentária.

Palavras-chave: Erosão dentária; Concentração de íons de hidrogênio; Soja. 